\title{
Entrepreneurship, Innovation and Strategic Foresight: How Entrepreneurs Engage the Future as Opportunity
}

\author{
Arran BROWN and Brian BARNARD*
}

Wits Business School, University of the Witwatersrand, South Africa

\begin{abstract}
This study investigates how entrepreneurs and innovators engage the future, and it reflects on how strategic foresight (also called futures studies) can contribute to innovation and entrepreneurship. The literature emphasizes the importance of planning for the future, but not much attention has been given to how entrepreneurs view, forecast and incorporate the future, and how this influences their innovation and creativity. The study found that entrepreneurs are disconnected from the future, and do not take it seriously. The future is mostly left to unfold, and it appears as a surprise. Entrepreneurs use simple methods to engage the future, and their understanding of it is vague. There is a lack of leadership and coordination around the future, and very little intervention around the future. Entrepreneurs recognize a general connection between the future and innovation, but they fail to see the relationship between innovation and futures studies. Futures studies are central to innovation, especially radical innovation, but entrepreneurs do not exploit it. Incremental innovation is predominant, and this leads to the conclusion that entrepreneurship is dysfunctional, to the extent that radical innovation is an important part of entrepreneurship and futures shaping. The study essentially surfaces a number of obscure philosophical positions regarding the relationship between entrepreneurship, innovation and the future.
\end{abstract}

Keywords: Entrepreneurship, strategic entrepreneurship, innovation, radical innovation, strategic foresight, futures studies, futures leadership

JEL Classification: O30, L26

\section{Introduction}

Organizations studied historical information to forecast and develop strategies for the future (Dator, 1996). However, as mentioned by Godet (2008), in today's rapidly changing and uncertain business environments the future is no longer forecasted, it is prepared. Organizations are proactively having to scan

\footnotetext{
* Corresponding Author:

Brian Barnard, Wits Business School, University of the Witwatersrand, South Africa

Article History:

Received 6 December 2018 | Accepted 3 February 2019| Available Online 11 February 2019

Cite Reference:

Brown, A. and Barnard, B., 2019. Entrepreneurship, Innovation and Strategic Foresight: How Entrepreneurs Engage the Future as Opportunity. Expert Journal of Business and Management, 7(1), pp.11-30.
}

This paper has previously been included in an open access repository - SSRN. 
their environments to better understand the future.

Foresight examines environments and helps create future scenarios (Vecchiato and Roveda, 2010). Foresight increases innovation capacity, and helps organizations simplify complexity (Heger and Rohrbeck, 2012). Uncertainty intensifies when organizations fail to scan environments effectively, and organizations then struggle to implement the right solutions when faced with change (Vecchiato and Roveda, 2010). Strategic foresight (SF), also known as futures studies (FS), is used to create different forward-looking views of the future, which helps organizations to identify opportunities and threats, and then to implement strategies to gain competitive advantage (Rohrbeck et al., 2007).

Innovation, and specifically radical innovation (RI), is seen as important for entrepreneurship. Incremental innovation merely builds on current ways of doing things, whereas RI completely changes the way people live their lives (Detienne et al., 2001). RI can result in a quantum leap and can generate significant outcomes. RI also involves innovating in areas where larger organizations have failed to identify gaps and new markets (Detienne et al., 2001).

As mentioned by Detienne et al. (2001), large organizations have hierarchical structures, and innovation is usually bottled-up by restrictive policies, while entrepreneurs have flexibility, and are better positioned to respond to opportunities and implement strategies quicker.

Given that the future is uncertain, entrepreneurs can benefit from SF practices, as outlined in the literature. SF is seen as an antecedent of RI, in that SF helps anticipate future change, which can lead to RI.

The purpose of this study is to investigate how entrepreneurs and innovators engage the future as opportunity. The following three research questions are addressed:

1. How do entrepreneurs view the future?

2. How do entrepreneurs engage and make sense of the future?

3. How do entrepreneurs incorporate the future when innovating?

A predominant focus of the research is to reflect on how SF contributes and can contribute to innovation and entrepreneurship.

\section{Literature Review}

\subsection{Strategic Foresight and Futures Studies}

Rohrbeck et al. (2007) note that futures research has progressed from forecasting to SF. In addition, SF helps companies deal with future change and to explore possible futures. SF was used to refer to research at company level, and today it is also called FS.

Vecchiato and Roveda (2010) mention that a company's external environment is an area of great uncertainty. The challenge is to identify threats and opportunities, and to react timely. More recently, the term SF is used, because it incorporates the full range of methods used to foresee change in the external environment and it emphasizes the relationship between foresight and strategy. Methods like environmental scanning help to understand the external environment and formulate strategies.

McKelvey and Boisot (2009) indicate that access to information can result in sustainable competitive advantage. Foresight is defined as the ability to make sense of perplexity and to identify opportunities ahead of competitors. SF considers forces in the external and internal environment.

Hines and Bishop (2006) recognize that successful companies do not ignore the future. Scanning is an ongoing process used to stay attentive to new ideas. According to Rohrbeck and Schwarz (2013), foresight looks beyond the organization or industry. Foresight does not predict; it illuminates the future. To understand future change, organizations need to broaden their perspective and vision.

Forecasting uses past data to anticipate the future, whereas SF prepares for change by delineating the future (Rohrbeck and Gemünden, 2008). SF helps inform companies about the external environment, which involves markets, technology and competitors (Rohrbeck et al., 2007).

\subsection{Futures Positions, Philosophies and Thinking}

Radical change can appear as a surprise, because humans think in stages and consume information in parts (Farrington et al., 2012). It is also common for society to believe that the future is a continual straightline projection of the current environment (Vecchiato and Roveda, 2010).

\subsubsection{Images of the Future}

Bergman, Karlsson, and Axelsson (2010) mention two different categories of forecasts, explanatory claims and truth claims. Based on these two forecast categories there are four types: 1) predictions; 2) prognoses; 3) science fiction; and 4) utopias or dystopias. These four types are used to determine different 
future outcomes.

Hicks (2004) argues that the future is unknown, and a single image of the future cannot be predicted, but alternative futures can be. Images of the future fall into three categories: 1) Tacit futures (spoken about, but not very clear); 2) Token futures (involves the future, but are not clarified well enough to make sense); 3 ) Taken-for-granted futures (involves an inevitable future, where no other future seems relevant).

Further to this, Dator (1998) suggests that images of the future are continually changing, due to differing opinions and diversity of cultures. Images of the future can be grouped into one of four categories: 1) Continuation - nothing changes, and business remains the same; 2) Collapse - external impact, terrorist attack, war or natural disaster; 3) Disciplined society - society being categorized according to values; and 4) Transformational society - society changing to new ways of doing things centred on "high-tech" values and changes in behaviour (p. 9).

Inayatullah (2008) agrees that there are a number of different images of the future, but mentions that five images are most typical. The five are: 1) Evolution and progress - increasing technological advancements and reasons for action; 2) Collapse - human beings have pushed it a step too far, creating an irreversible dark future; 3) Gaia - creating partnerships to repair the damage we have created for ourselves; 4) Globalism sharing a global society, breaking down borders and opening up opportunity for all; 5) Back to the future - we have created a world of chaos and should return to a world with less complication and radical change (p. 7).

\subsubsection{Determinism and the Role of Humans}

Humans have a natural capacity to consider alternative futures and make decisions in the present that will influence the future (Slaughter, 1996). Slaughter (2002) mentions that if humans were able to predict the future accurately, the world go by as we expected. If humans can understand environments, they can successfully predict futures. The world around us is evidence that humans have the desire to control outcomes. What is being done requires looking into the future and making predictions.

Godet (2008) believes the future is prepared, and not forecasted. Present human behaviour can explain future desires. In a world faced with rapid change and uncertainty, humans have to innovate continually. By understanding the consequences of ignoring the future, humans can action strategies to help realize the desired future.

Further to this, Dator (1996) argues that the future can be grasped and planned, but three important trends need to be examined first. The first is that the future is a continuation of the past and present. The second is that unfolding events are cyclical and historical information can provide an image of the future. The third trend is that new technologies are being developed as a result of "emerging issues". Emerging issues may not seem evident in the present and have not existed in the past, but appear when change is apparent. As a result, humans are developing technologies to help mitigate these issues.

\subsubsection{Futures Thinking}

FS help simplify the processes of dealing with change so that informed decisions and actions can be taken to create the desired future (Inayatullah, 2008).

With this in mind, Inayatullah (2008) has listed six concepts of FT. These are: 1) The used future; 2) Disowned future; 3) Alternative futures; 4) Alignment; 5) Model of social change and 6) Use of the future. The first concept, the used future, describes a future that may have been influenced by another country or culture without being consciously aware of it. FT is influenced by trying to find ways to reverse global issues that have been created. The second concept is disowned future, which describes an ignored future, because we are only focused on the present. The third concept is alternative futures, which mentions that we have become solely fixated on one future and forgotten to consider alternative futures. The fourth concept, alignment, highlights the importance of aligning our desired future with the right strategy. The fifth concept, model of social change, includes what people believe influences the future. Does the future just happen, or do you get up and make it happen yourself? The sixth concept, use of the future, mentions that FT helps gain new skills and improves foresight. Understanding the future enhances creativity and innovation. Encouraging FT builds confidence and provides independence (p. 5).

\subsection{The Contribution of Strategic Foresight}

Fink and Schlake (2000) mention that SF involves input from different stakeholders, and scenario planning (SP) has four different scenario functions, these are: 1) Decision support; 2) Creation of orientationknowledge; 3) Communication of future developments, and 4) Stimulation of strategic thinking (p. 44).

Cook, Inayatullah, Burgman, Sutherland, and Wintle (2014) explain that SF is useful for making longterm planning decisions. These include: 1) Monitoring existing problems; 2) Highlighting emerging threats; 
3) Identifying promising opportunities; 4) Testing the resilience of policies, and 6) defining a research agenda (p. 8). SP can illuminate possible futures, which can be linked to ways of thinking and decisions made (Slaughter, 2002). Slaughter (1997) notes that organizations no longer need to react to competitors or wait for market demand if SF is used effectively. A forward view of the foreseeable future helps management shape the strategy of the organization.

\subsubsection{Learning}

Rohrbeck and Schwarz (2013) indicate that foresight is successfully implemented by carrying out a process of unlearning and relearning. "Foresight activities should be a structured communication process focusing on mental models, blind spots and knowledge gaps" (Rohrbeck and Schwarz, 2013, p. 16). Images of the future are influenced by life experiences, which means humans have difficulty processing new ideas, because of the way they understand the world to be. This highlights the importance of using scenarios to create tangible "images of the future". Images are stored in management's memory. Recalling these memories of the future helps organizations deal with change. SF contributes to a learning organization by creating memories of the future.

\subsubsection{Proactiveness}

Slaughter (1997) emphasizes that SF is not limited to long-term predictions, it is also important to incorporate into daily management processes. To remain competitive, organizations need to focus on present challenges, before they concern themselves with the future. Environmental scanning identifies threats and opportunities. Competitive advantage is gained by taking advantage of opportunities, making quick decisions and implementing calculated strategies. Using SF in the short-term urges organizations to proactively give thought to their immediate environment. SF should be an established practice in organizational cultures.

\subsubsection{Original Thinking}

Hines (2006) indicates that forecasting processes question organizational beliefs, that the future will be similar to the past. Forecasting encourages people to think and act differently. Rohrbeck and Schwarz (2013) add to this by mentioning that SF brings people together for discussions. Scenario analysis allows a diverse group of people to share their differing opinions and insights. Challenging mental models reveals gaps and captures a broad view of the environment. SF enhances collective intelligence and challenges "follow the crowd" ways of thinking.

Slaughter (1997) states that SF provides alternative ways to deal with past cultural challenges that have carried over into today's world. Some of these are; exploitation of resources, man with no limits, economic growth at all costs, and exponential technology growth (dehumanized). SF can provide sustainable alternatives in an attempt to deal with these present challenges that seem to be ignored.

\subsection{The Scope and Elements of Foresight}

According to Vecchiato and Roveda (2010), lack of information and awareness leads to uncertainty. Uncertainty escalates when management do not scan their environments effectively enough, and then do not build solutions to cope with change. There are three types of uncertainty that function together, which determine the level of uncertainty an organization may be exposed to. These are: 1) State uncertainty - lack of awareness around how the environment may change; 2) Effect uncertainty - lack of ability to predict how changes in the environment may affect the organization; and 3) Response uncertainty - lack of ability to make the right decisions and implement the right actions in response to change (p. 1529).

Vecchiato and Roveda (2010) go on to mention that foresight has predominantly always been focused on the science and technology environments (technology foresight). Social media and marketing activities help determine future environmental change, such as customer needs, consumer behaviour and lifestyle trends (social foresight). If organizations can build social foresight predictions, they will be better positioned to increase new technology sales in the future. Foresight also involves strategic competitor analysis, which aims to identify key competitors and assess what they are doing in the market. These three areas of foresight focus on organizations' micro-environments. Foresight research extends further and also includes the political, economic, social, legal, environmental, technological and political environments (PESTEL). A PESTEL analysis focuses on the external macro-factors that could affect an industry as a whole.

Further to this Vecchiato and Roveda (2010) note that the scope of analysis derived from a customer needs analysis involves three levels. These are: 1) Macro-level analysis - different segments of a broadly defined industry; Meso-level analysis - focuses on a particular market or industry; and 3) Micro-level analysis - a specific organisation or business unit. The results from the strategic analysis involving these three areas 
will determine who the decision-makers are and at what level in the organization. Meso and macro-level decisions involve the long-term, while micro-level decisions deal with the short-term (p. 1530).

Rohrbeck et al. (2007) add to this by mentioning that SF involves three areas: science and technology, socio-cultural, and the competitive environment. The primary research fields within SF are: 1) Technology intelligence; 2) Competitive intelligence; 3) Political environment foresight; and 4) Consumer foresight. Technology intelligence involves the use of weak signals to detect new and old technologies. Competitive intelligence is a process of collecting information to understand the competitive environment better. Political environment foresight involves the assessment of policies, laws and regulations in different environments. Consumer foresight involves getting closer to your customers to understand their wants and needs, as well as demographics and potential behavioural changes (p. 3).

\subsection{Foresight and Innovation}

Rohrbeck and Schwarz (2013) suggest that SF and innovation are closely associated. SF processes include creativity and innovation, while searching for weak signals is the same as searching for innovations. SF helps new product development in the following three ways: 1) Exploring new areas of innovation; 2) Identifying possible innovations; and 3) Challenging research and development (R\&D) teams. Scanning the environment for new technologies is standard practice in most organizations. However, scanning for future customer needs is less frequent. SF is used to determine new markets and customer groups. In cases where markets and industries merge, SF tools have contributed towards an improved understanding of the markets.

Further to this, SF is also used to cross-check whether or not current innovation strategies are aligned and prepared for potential future change (Rohrbeck and Schwarz, 2013). Farrington et al. (2012) explain that RI teams struggle with the challenge of extended time horizons and being able to predict whether or not present product development will be relevant in the future. Technological innovation is usually beyond the company's time horizon. SF helps organizations deal with time horizons.

A number of organizations use SF methods to increase innovation capacity (Heger and Rohrbeck, 2012). Heger and Rohrbeck (2012) emphasize that innovation should form a central role within an organization, to remain competitive, by keeping up with change. In an attempt to remain relevant, organizations need to improve internal processes and implement incremental changes to products and services, and continuously scan for new opportunities and markets.

\subsection{Business Context}

Heger and Rohrbeck (2012) explain that new markets are complex and uncertain. Foresight activities implemented in a business context help inform long-term decisions and illuminate potential futures, which help create innovations and inform strategies.

Further to this, Heger and Rohrbeck (2012) note that operating in complex and uncertain environments can result in a situation where knock-on effects or issues are difficult to identify. If an organization does not know what technologies are required to manufacture a specific product, it is impossible to determine product specifications. If the product specifications are uncertain, the organization cannot determine how much consumers are willing to pay. If there is consumer uncertainty and difficulty understanding how much they are willing to pay, the business may not be financially viable. With such uncertainty, it is difficult to make critical investment decisions. SF methods can help reduce risk and simplify complex relationships.

Slaughter (1996) argues that most organizations are starting to see the advantages of being strategically alert, and those that do not end up collapsing. Business approaches to SF and futures seem to lack sound findings, because more often than not they have come to accept that their way of doing things is the only way. Organizations that find themselves in this trap may suffocate critical thinking and miss opportunity, which sustainable social innovation depends on.

Hines and Bishop (2006) mention that the majority of organizations think the future will be an extrapolation of the past. Instead of creating a desirable future, they let events unfold on their own. Organizations need to change behaviours and engage the future.

Vecchiato and Roveda (2010) found that the role of managerial and organizational intellect in the way uncertainty is handled, is an essential area of research. Beliefs and mental models serve as a foundation for SF. Management's ability to make sound decisions can be restricted by the quality of information they receive. Mental models are developed to make sense of complex environments. These deeply-rooted mental models can negatively affect judgment, and inhibit the ability to think outside the box. Managers with differing perspectives of the environment, facing similar issues, often implement very different solutions from one another. Foresight brings clarity and enhances creative thinking.

Rohrbeck and Bade (2012) affirm the need for organizations to continuously scan for technological 
developments and market trends, to remain competitive. The business environment has progressed from "make-and-sell" to "sense-and-respond" (p. 6). The environment is becoming more competitive, and in dealing with rapid innovation, organizations are having to sensitize themselves to external change, and then quickly implement strategies to avoid threats and embrace opportunities. Foresight forces organisztions to look beyond their immediate businesses and industries.

Heger and Rohrbeck (2012) state that organizations have difficulty transitioning into areas of new business for a number of reasons. These are: 1) The current business is focused on core competencies, and new areas of business are forgotten; 2) Top management deal with multiple flows of information, which can be confusing, and the inter-dependencies may be difficult to grasp, which inhibits opportunity; 3) Emerging business opportunities are assessed by middle management, who may turn a blind eye in an attempt to avoid harming current business; and 4) Organizational structures have become too complicated, causing stagnation and missed opportunities.

Therefore, information gathering through foresight activities should be shared throughout the organization, and involve all relevant people. Foresight activities can help explore new business areas, by creating collaborative and creative work environments (Heger and Rohrbeck, 2012). This is further emphasized by Rohrbeck and Schwarz (2013), who mention that middle management are usually the most resistant to RI, and that SF creates value by bringing all key stakeholders together.

Vecchiato and Roveda (2010) mention that business managers need to be aware of important drivers of change. Drivers of change can influence the industry composition and the competitive environment, as well as how organizations add value to their customers.

\subsection{Level of Analysis}

McKelvey and Boisot (2009) explain that strategy-finding processes should contextualize and make sense of information to determine the environment. Extending social networks improve the organization's ability to understand the environment and respond quicker. The "where to look first" involves the long-term and current trends, which helps organizations understand the influencing forces. Complexity science can be used to break down complex trends into more simple and precise trends.

Rohrbeck, Mahdjour, Knab, and Frese (2009) mention that literature on environmental scanning incorporates factors that help select information. The scope of scanning covers different areas, such as technology, consumers, competition and political environments. The intensity of scanning determines how indepth one goes within these areas. Organizations within different industries scan areas that are relevant to their core competencies; this leads to narrow observations. Scanning vertically and horizontally is a necessary process to detect threats and opportunities.

\subsection{Future Study Methods}

Rohrbeck et al. (2009) mention that most organizations tend to use traditional methods that have always worked. Organizations with effective FS processes regularly adapt their methods according to the context within which they find themselves. Most organizations use simple methods, rather than the more complicated methods offered. An overview of the different FS methods are provided below:

Analytical methods: Slaughter (1997) mentions that cross-impact analysis is best used when forces have been identified and the connections between them need to be carefully examined. Analytical methods are used to create scenarios and scanning processes. Forecasting and trend analysis have become less popular, because sudden change can influence them.

Iterative and exploratory methods: Slaughter (1997, p. 7) notes that the following methods are best used to assess future options and strategies. These are:

- Scenario building: This is the most widely used method in futures study. Scenarios help organizations understand the immediate environment, consider future states and then implement strategies;

- Visioning: This is a workshop process studying current issues, considering past successes and then determining a way forward to realize a preferred future;

- Backcasting: This method is used to study a desired future and then working from that backwards to the present; each step is carefully assessed;

- Future-scan: This method is usually carried out over a two-day workshop and results are entered into a cross-impact matrix. The outputs provide three images of the future, which are then assessed to help build strategies.

Implications wheels and futures wheels: Cook et al. (2014) mention that futures wheels are used to determine the implications of decisions. A group discussion first highlights the primary concerns, and after 
that, other potential knock-on effects are considered. Inayatullah (2008) argues that futures wheels are used to determine future issues, and how the working parts in a system all work together to form a bigger picture. Farrington et al. (2012) explain that implications wheels are a qualitative tool used to assess how trends change over time. The process requires group input, and together different potential future forces are mapped out. This allows organizations to prepare for future surprises.

Participatory futures: Farrington et al. (2012) mention that this is a new method that uses online simulation type technology. The advantage of using this method is that it captures a sizeable, diverse audience, which can help predict the future and then devise ways to adapt.

The futures landscape: Inayatullah (2008) notes that this is a tool to help organizations understand where they are positioned. The landscape deals with four layers: the first is a highly competitive environment where the firm is merely surviving. The second is using strategy to remain attentive and improve. The third is a bird's-eye view of the environment in which the organization finds itself, and the fourth layer is understanding the vision and a way forward into the future. Are organizations in survival mode and only focused on the dayto-day operations, or has it created a forward-looking strategy to grow?

Emerging issues analysis: Cook et al. (2014) describe this as a method used to detect future trends, by examining potential associations between unrelated factors. Dator (1998) mentions that emerging issues analysis (EIA) is a method used to identify threats and opportunities early on, before they develop and become too difficult to manage. Inayatullah (2008) states that EIA is also concerned with identifying progressive and innovative business areas.

Scenarios: Rohrbeck and Schwarz (2013) note that scenarios create value by simplifying change, presenting alternative futures and building strategies. Fink and Schlake (2000) mention that scenarios help organizations remain competitive, by creating multiple views of the future, because one single image of the future is unreliable. According to Mietzner and Reger (2005), SP helps create multiple future options, and this helps with decision making.

A scenario is not a fixed future, it is an image of a possible future, which then informs what needs to be done in the present to move closer to a preferred future state (Godet, 2008). Farrington et al. (2012) describe two different types of scenarios, 1) Inductive scenarios are created from a bottom-up approach, looking at trends and building alternative futures, and 2) Deductive scenarios which use a top-down approach, taking a few known critical uncertainties and creating scenarios around how they might play out.

Backcasting: This is a tool that can be used to identify factors that may hinder the achievement of goals, and then develop strategies to deal with them (Cook et al., 2014). Backcasting is not a forecasting tool; it is a tool that tests the likelihood of a desired future being achieved (Robinson, 1990). Slaughter (1997) explains that backcasting is a process of working back from the desired future and putting in place the steps required to get there. This method mainly deals with long-term issues, rather than present immediate problems.

Competency trees: Godet (2008) notes that competency trees are a representation of the entire organization. This method is used to understand the organization's strengths and weaknesses. The analysis includes understanding the past, examining the present, and looking ahead to the future. The roots represent the skills and capabilities, the trunk represents the output ability, and the branches and leaves represent the market, services and products.

Structural analysis: Godet (2008) mentions that structural analysis is carried out by internal staff, as well as external consultants. The method follows three stages: 1) identifying a range of factors, 2) understanding connections between these factors, and 3) selecting the primary factors. The real advantage is that it stimulates group think and it can be used to validate hypotheses.

Stakeholder analysis: Godet (2008) notes this method helps identify the relationships between various strategic stakeholders, and to understand the influence of each stakeholder. During the analysis, important questions are put together, and a strategic direction is formulated.

Morphological analysis: Godet (2008) mentions that this method is predominantly used to break down a wide variety of alternatives and build scenarios. Ritchey (2005) argues that morphological analysis is used to deconstruct and understand a range of complicated relationships, usually referred to as wicked problems. It entails understanding the parts that make up a whole.

Delphi method: Cook et al. (2014) explain that Delphi method (DM) is a process where experts carry out rounds of questions and answers, and according to the view of others, they can adjust and improve their own views. A confidential voting system is used to enhance accuracy. Slaughter (1997) argues that DM inhibits diversity, because opinions are limited to subject matter experts only. However, the method does capture farreaching views, and can be useful when experts are knowledgeable. Godet (2008) mentions that DM is a process that provides expert consensus on an issue facing uncertainty.

Causal layered analysis: Causal layered analysis (CLA) is a tool used to uncover hidden beliefs and 
create new platforms to enable change (Cook et al., 2014). CLA studies issues thoroughly, in contrast to traditional forecasting tools which usually only touch the surface of issues (Slaughter, 1997). CLA is not a futures predicting tool, it is a tool used to deconstruct the past and present, in an attempt to construct alternative futures (Inayatullah, 1998). Further to this, Inayatullah (2008) mentions that CLA is a tool used to deepen our understanding of the future, and there are four areas to consider: 1) the day-to-day, generally accepted way of doing things, which mainly deals with the short-term; 2) a more in-depth assessment of the political, economic and social causes of an issue; 3) worldview, the way we make sense of the world we live in; and 4) uncertain, but trusted experiences. CLA attempts to create understanding by bringing these four areas together and unpacking them.

Action learning: Ramos (2006) notes that action learning (AL) is a learning process carried out by asking a group of contributors questions; it is not a collection of expert opinions. Images of the future are created in a collaborative setting. Present strategic action shapes the desired future. Inayatullah (2006) emphasizes that AL is a learning process gained through practical experiences. The official future is questioned, unpacked and new futures are created.

\subsection{Conclusion}

The literature review delineates the importance of considering and engaging the future. The business environment is faced with rapid change, RI and ever-growing uncertainty. Organizations are forced to consider future alternatives, innovate and implement strategies, if they wish to gain competitive advantage and stay ahead of the curve. The literature review also shows how engaging the future can have an impact on innovation, and thus entrepreneurship. However, the literature is generally silent on how entrepreneurs view and approach the future, and what they are actively doing in preparation for and anticipation of the future. The review concludes with 3 research questions, in light of the principal question: How do entrepreneurs and innovators engage the future as opportunity?

- How do entrepreneurs view the future?

- How do entrepreneurs engage the future?

- How do entrepreneurs incorporate the future when innovating?

\section{Methodology}

In order to answer the research questions regarding how entrepreneurs and innovators engage the future as opportunity, purposive sampling was used, and semi-structured interviews were carried out with experienced entrepreneurs. It is the view that experienced entrepreneurs would have developed adequate knowledge and experience - views and perspectives - regarding the future, and innovation in the context of the future. Experienced entrepreneurs were defined as entrepreneurs with at least 1 successful business, and with a minimum of 3 years entrepreneurship experience. Sampling was not confined to any particular industry, as the impact of industry on views and perceptions of the future, as well as approach to the future, was seen as negligible. A total of 10 interviews were conducted. Participants were identified through professional and business networks. Interviews on average lasted 1 hour. Interviews were recorded, transcribed, coded, and further analysed.

\section{Analysis}

Table 1 presents the main themes of the analysis, with their associated research questions.

Table 1. An overview of the research questions and grouped themes.

\begin{tabular}{|l|l|}
\hline Research Question & Related Themes \\
\hline 1. How do entrepreneurs view the future? & $\begin{array}{l}\text { Outlook of the future } \\
\text { The future brings change } \\
\text { Preferred futures }\end{array}$ \\
\hline $\begin{array}{l}\text { 2. How do entrepreneurs engage and make sense of the } \\
\text { future? }\end{array}$ & $\begin{array}{l}\text { Considering futures } \\
\text { Factors influencing the future } \\
\text { Futures studies }\end{array}$ \\
\hline $\begin{array}{l}\text { 3. How do entrepreneurs incorporate the future when } \\
\text { innovating? }\end{array}$ & $\begin{array}{l}\text { Innovation and the future } \\
\text { Competitive advantage } \\
\text { Acclaimed entrepreneurs (Elon Musk, etc.) }\end{array}$ \\
\hline
\end{tabular}




\subsection{How Do Entrepreneurs View the Future? \\ 4.1.1. Outlook of the Future \\ Perspectives:}

The participants' outlook of the future was generally negative. The main factors driving this are political and economic uncertainty, lack of leadership, a culture of dependency, poor infrastructure, lack of education and skills, government regulations and policies, growing unemployment, and restrictive labour laws. Further to these factors, the views showed that people are concerned and worried about the future. The business environment is seen as turbulent and tough. It was mentioned that there is a lack of interest in entrepreneurship as a career choice, and government support is limited.

Participants were also optimistic and hopeful, and mentioned that the future looked promising. The future was described as new, intriguing, exciting, and brighter than most think. It was mentioned that access to the internet and technology is encouraging entrepreneurial activity, more business schools and incubators are opening and stimulating business, and government are starting to improve in the incubation space. The view was that people are finding long-term solutions to past issues, and the future would bring opportunity for entrepreneurs.

There were a few mentions that outlooks of the future are context-based, where certain futures look promising and others horrifying. A participant said, "In South Africa, it is so hard to predict, it could go any number of ways. It could go more crumbly, and less infrastructure, and more nonsense, and more corruption, and it could have little pockets of places where it really excels, which is probably what will happen. And other places where it will stagnate."

\section{Uncertain and surprising:}

The view was that the future is mostly uncertain and surprising, and it is continually changing, and disruptions appear unexpectedly. It was mentioned that the future is difficult to predict, and that it is mostly a guess. The main factors causing this are unpredictable events, disruptive innovations, waiting for the future to arrive, and highly volatile and changing environments.

Participants mentioned on very few occasions that the future is not surprising and unexpected. The view was that there are many weak signals and obvious trends that show where the future is going. One participant said, "I think in general terms, for me it is not surprising at all. I think that there are enough signs about what the future would look like." It was also mentioned that research provides sufficient insights into the future. There were a few instances where participants felt neutral about the future being surprising and uncertain, and said maintaining an awareness of the future can reduce uncertainty and minimize surprises, but it cannot be avoided.

\section{Fixed or knowable:}

The view was that the future is unknown and cannot be fixed. It was also mentioned that the future is difficult to predict, complex and continually changing. It was mentioned that the general direction of the future can be partially anticipated, but how one arrives at that future is unknown.

\section{Business structures and environments:}

The predominant view was that businesses are changing from centralized to decentralized structures. Participants mentioned on many occasions that traditional hierarchical structures will not be sustainable in the future, and that there is a shift towards flat structures. The view was that flat structures promote openness and trust, collaboration, networks, and sharing of information.

Another common view shared by participants was that company structure will influence the ability to change, and that smaller organizations can change quickly. As an example, one participant said, "when you have a small organization, and you change, it is easier, because, you know, the shift in change does not disrupt things, but when you have a big organization with lots of people who are used to doing things in a particular way, and there is a big expectation by everybody, all stakeholders, it is not easy."

Further to this, it was mentioned that the future would be made up of many smaller entrepreneurial businesses, and fewer monolithic corporations. The view was that traditional norms are changing, and new norms are being created. It was mentioned that traditional economic drivers will change, and new developments and areas of research will start creating new industries. New norms mentioned were flexible work schedules, self-employment, and people enjoying a balanced lifestyle. 


\subsubsection{The Future Brings Change \\ Rapid change:}

The dominant view was that the future will bring exponential change and disruption, and that innovations are changing the way people live their lives. Participants mentioned that change is exponential, and described it as "bothersome" and "worrying". As an example, one participant said, "we develop a product, or we develop a version of our product, which is all obviously software based, and we are releasing new versions and innovating on those things literally daily."

Participants mentioned that it is essential to be agile and adaptive, to remain relevant in a rapidly changing world. As an example, one participant said, "because the future changes so fast, variables are changing so fast, circumstances are changing so fast, you have to be so agile in adapting to it." The view was that agility could help mitigate the effects of surprises.

Participants mentioned that people generally resist change and keep doing things in familiar ways. The view was that there is a "generation" of people who are scared of the future and resist change. It was said that people who ignore new technologies will soon become irrelevant. Also, the view was that people need to be open-minded and willing to learn, and that innovation should be an on-going strategy.

\subsubsection{Preferred Futures}

\section{Realizing better futures:}

The view was that social media is changing the way society behaves. One participant said, "I mean social media is changing everything. But the problem is, that I am seeing develop, or that I am concerned about let me rather say, is that you have a lot of commentators that actually have no real cause to be a commentator, and they are becoming like a mob." It was also mentioned that social media divides society, by spreading fake news and information.

Participants mentioned that technological development and advancement, like the fourth industrial revolution, is causing social conflict, further inequality, privacy and security issues, and is threatening jobs. It was also mentioned that peace on earth is being disrupted by global conflict, and environmental damage is increasing; these are concerns of the future.

Participants mentioned that the business environment needs reviving, and that entrepreneurship needs to be encouraged, to help reduce unemployment. It was mentioned that education systems need to teach entrepreneurship and transfer skills, to enable people to start and manage businesses sustainably. The view was that entrepreneurs need more support from the government, including better infrastructure and policies that encourage people to start businesses and to become innovative.

The dominant view was that better futures are subjective, and context based. It was mentioned that poverty and income inequality need to be addressed urgently. As an example, one participant said, "it is at a point that no entrepreneur, no business person, who has any hope for the future, and wants to build for the future, can do so without considering how what they do, will alleviate poverty".

Participants mentioned that the economy needs the be inclusive, jobs need to be created, and greater society can no longer be ignored. A number of participants mentioned that imbalances of the past still need to be restored. Social injustices need to be considered, and people need to become more aware of them.

\section{Moral and ethical considerations:}

The view was that there are moral and ethical considerations involving technology and long-term social consequences. New products need to benefit society as a whole. Participants mentioned that some organizations are extractive, and generate profits at all costs. It was also mentioned that keeping people in poverty, while others enjoy wealth, is a moral issue. As an example, one participant said, "I don't know if anybody can enjoy their wealth, with somebody standing in abject poverty right next to them. How can they still call themselves human?"

\section{The ignored future:}

The view was that people are willingly blind to undesirable futures, and there is a lack of ownership of the future. People feel that today's wrong-doings will be dealt with by future generations. Participants mentioned that futures are ignored when there are economic agendas involved. One participant mentioned that the future is ignored when significant investments depend on a specific future playing out.

Participants mentioned that the future is ignored, because it is unknown and scary. As an example, one participant said, "If you can't predict it, you don't know what is in it, and it looks terrifying, you just turn your head and focus on what you can". 


\subsection{How Do Entrepreneurs Engage and Make Sense of the Future? \\ 4.2.1. Considering Futures \\ Understanding futures:}

The majority of participants mentioned that they actively attempt to understand the future. The main view was that entrepreneurs cannot remain relevant in a fast-paced world, without being cognizant of the future. Understanding the future helps identify opportunities and avoid threats. It was mentioned that understanding of the future does not eliminate risk, it reduces it by being prepared for the future. Participants said that thinking about the future provides direction, and helps inform immediate decisions. Considering futures was described as, "something to head towards" and "a viable compass". A few participants mentioned that entrepreneurs deal with the day-to-day of business, and considering the future is not a priority. Others mentioned that a lack of time makes it difficult to keep up with the future, and one participant mentioned that the future is unknown, and the time spent on it is irrelevant.

\section{Personal futures:}

The view was that personal future planning is necessary, but more effort was required. Thinking about futures was described as a "good intellectual exercise" and a "valuable planning process". Most participants mentioned that planning personal futures is an informal activity, and a general idea is mapped out. As an example, one participant said, "I guess mine is just more informal and maybe scrambled up here in my head". One participant mentioned that the future keeps changing, and it never ends up as planned. Another participant mentioned that the process of thinking about the future is of "no interest" and said the process is "tiring".

\subsubsection{Factors Influencing the Future \\ Trends and influencing forces:}

The view was that the world is moving from centralization to decentralization. It was mentioned that digital technology, automation, and big data are current significant trends, and that digital marketing will slowly start declining.

\section{Following the future:}

Participants were asked to rank a number of factors according to their level of importance in terms of influencing the future. Figure 1 below shows the number of responses and rankings for each factor. Participants placed most importance on technology and social factors influencing the future, and least importance on political factors and competitors.

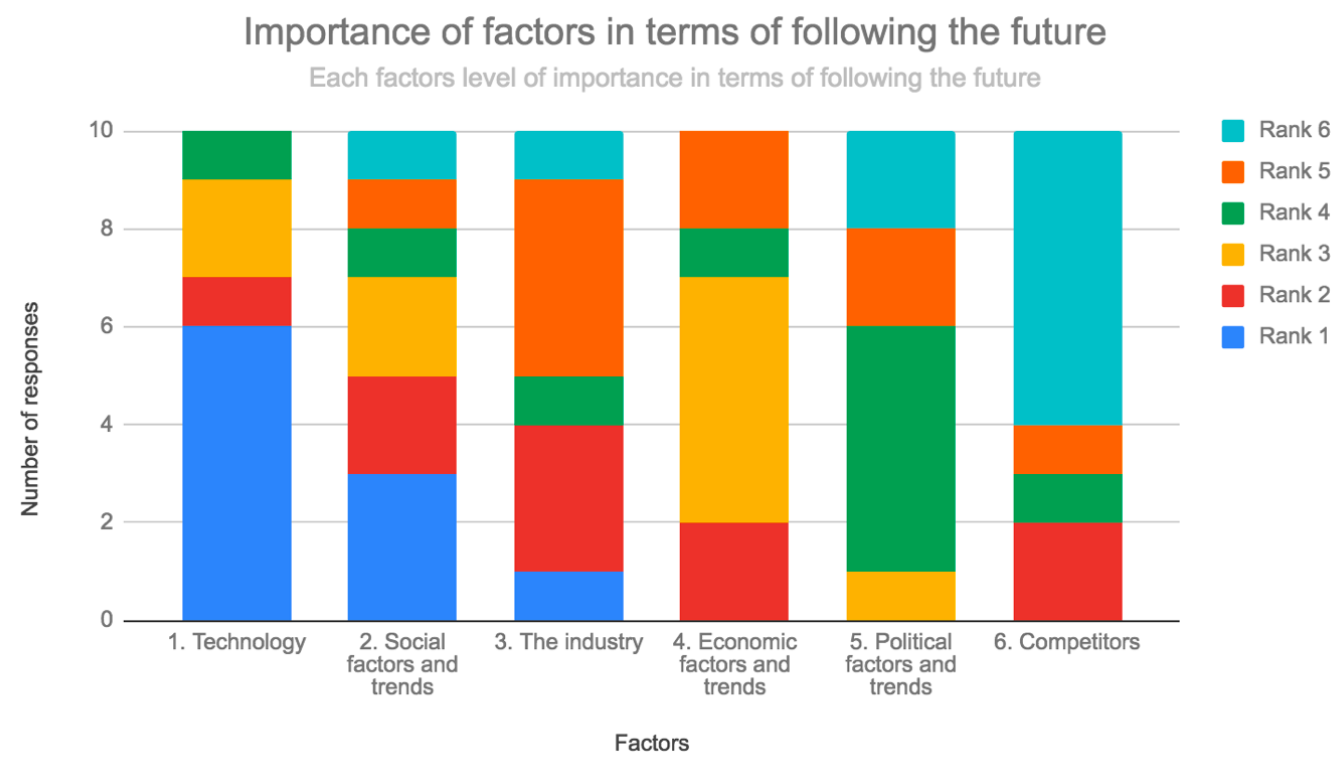

Figure 1. Importance of factors in terms of following the future.

\section{Past and present influence on the future:}

The view was that an understanding of the past is helpful in constructing views of the future. Participants said, lessons from history inform today's decisions, which then influence the future. One participant mentioned that a lot of today's innovations are based on what was done in the past (incremental 
changes), and that future innovation attempts to resolve the problems of the past.

Participants mentioned that unpacking the present helps create tangible images of the future, but it does not make the future predictable. The view was that it is essential to understand the present, and then to continuously adjust and predict where the future is heading. Participants mentioned that the future is imagined and unpredictable, and therefore understanding the present is irrelevant. It was mentioned that people can get stuck in the past and resist change, this then impacts the future, often negatively.

\section{Factors directing the future:}

The view was that many leading factors influence future direction. The main view was that entrepreneurs have the most significant influence, and that they usually do not intentionally plan to change the world, it just happens. As an example, one participant said, "I just think Steve Jobs was passionate about computers and how they looked. Elon Musk is passionate about certain technologies. By extension they impact the future, I don't think they set out to change the future." Another view was that innovations redirect the future, as one participant said, "so, innovation will shape the future. That is just the nature of innovation."

Participants also mentioned that worldviews and agendas direct and shape futures. Governments and global bodies drive agendas, formulate regulations and policies, and control access to information and knowledge, which influences society, and this shapes futures. Another view was that society has a significant influence on the future, because society decides if an innovation meets a need, and if it does, people end up changing. One participant said, "I think this is where, when you talk about the ordinary citizen, it is the adoption of the ordinary citizen of the innovator's product or services that will shape the future."

Participants also mentioned that humans are processing and accessing information far quicker, and this shapes the future too.

\section{Views of others:}

Participants mentioned that the views of others do influence their views of the future. However, a common concern was that opinions are often biased, and drive agendas. The view was that information needs to be trustworthy and credible, for it to be useful. One participant said, "so, you get dreamers, and you get some people who have a very respected and a very sort of credible view of what that future might be. So, I pay attention to those."

Another common view was that there are many differing opinions on the future, and a lot of them can be wrong. It was mentioned that people need to trust their judgements, and then formulate their own views, and not just follow others blindly. Participants also mentioned that incorporating ordinary people's views and public perceptions, help identify gaps and needs. It was mentioned that many views of the future are developed in a first world context, and then "fail" in a third world context.

\section{Assumptions made:}

The view was that the future is difficult to predict, because things change very quickly, and predictions are often wrong, because the future is unknown and uncontrollable. One participant said the future is a "game of probabilities", emphasizing that it is difficult to predict the future. Participants mentioned that the following factors usually unsettle future projections:

- Lack of resources.

- Fixed views of the future.

- Overconfidence.

- Caught in the day-to-day of the business.

- Lack of credible information.

- Slow uptake from markets.

- Disruptive innovations.

\subsubsection{Future Studies}

Studies on the future:

Participants mentioned that they are generally not aware of FS conducted for entrepreneurs. The view was that FS for entrepreneurs would be beneficial, but hidden agendas and credibility would be a concern. It was mentioned that FS carried out in first world contexts, need to be made relevant to third world contexts. Another view was that FS could develop a "herd mentality", where everybody believes in one idea or outcome, and this carries risk. 


\section{Methods used:}

Participants mentioned that traditional forecasting methods, like financial analysis, are used to map future direction. Common methods used were reading books and publications, engaging social media platforms (LinkedIn), attending conferences, creating mind maps, asking questions and learning, dialogue and discussion, international travel, watching science fiction movies, and analyzing general trends. Some participants said they use tools such as SWOT, PESTEL, Delphi programs, the Business Model Canvas, Porter's 5 Forces, and scenario analysis. The majority of participants said they continually scan for weak signals. One participant said competitor and industry analysis, and benchmarking techniques, are used to map future direction.

\section{Future timelines:}

Participants mostly use short-term timelines when working with future predictions. The general view was that extended timelines are unpredictable and risky, and shorter timelines are less risky. Participants mentioned that rapid change is shortening timelines: in the past, timelines of 5, 10, 20 years where relevant, but the view is that timelines have been reduced to 6-18 months, and in some cases, 3-5 years. Participants mentioned that rapid change can make future planning irrelevant, and therefore it is done as an exercise, rather than a set strategy. As an example, one participant said, "So, you do it, and you kind of put it in the drawer, and then you realize that, in a year or two, that it is probably not relevant." Participants mentioned that entrepreneurs can work with timelines of 10-20 years, but unlimited resources are required. As an example, one participant said, "maybe you can have these big visions like Elon Musk has, or we have like a world where there are driver-less cars, so yes, if you have unlimited cash to burn, sure."

\subsection{How Do Entrepreneurs Incorporate the Future When Innovating? \\ 4.3.1. Innovation and the Future \\ Understanding the future:}

The view was that innovation and the future are deeply linked. Participants mentioned that it is essential to incorporate the future when innovating, and that attempting to understand the future helps identify opportunities, reduces uncertainty, and ensures innovations are future ready and sustainable. Participants mentioned that new product developments are only successful when consumers buy them, which means entrepreneurs need to study future trends, to prepare for future needs.

The majority of participants said that RI could not exist without viewing the future. As an example, one participant said, "I don't believe that you can create radical innovations, if you don't understand what people's mindset is now, and what future events are coming".

Another view was that radical innovations result when entrepreneurs quietly try to resolve a problem, without studying the future, and the innovation takes off, because the market wanted it. As an example, one participant said, "Do you think Mark Zuckerberg knew that he was going to dramatically change the world when he created Facebook? No. Sometimes the most radical things come, because someone is trying to come up with a solution for themselves."

\section{Present issues and needs:}

The dominant view was that entrepreneurs are more concerned about innovating to solve immediate consumer needs, and this ends up shaping the future. Participants mentioned that scanning the environment to understand present societal and market demands, leads to innovation. The view is that entrepreneurs need to be aware of the future when innovating, but today's problems come first. One participant said, "it is more about deconstructing the present, in terms of product innovation, to say what are the things people are currently struggling with, or what are the needs currently, and that shapes the future."

\section{New product failure:}

The main view was that innovations mostly fail because they do not address immediate consumer needs. Participants mentioned that an understanding of the future is necessary for successful innovations, but it does not eliminate risk. The main factors that lead to new product failure, as mentioned by the participants, are:

- Products are too early for the market.

- Competitors produce superior products and get to market quicker.

- Technical issues.

- Innovating for an anticipated future based on assumptions, and it ends up wrong. 
Risk:

Participants mentioned that innovating for the future is risky, because the future is uncertain. The view was that innovating for the future in advance is risky, because innovation in general is expensive, and with limited financial resources, it carries significant financial risk. It was mentioned that the level of risk an organization decides to take on, depends on its culture. The view was that entrepreneurs need to innovate to remain future-proof, and that successful innovations entail risk.

Participants mentioned that incremental innovations are manageable, cheaper and less risky, and smaller changes made more frequently are less disruptive than sudden, significant changes. One participant mentioned that significant innovation is highly risky, because the market may not adopt it. The view was that incremental innovations could be developed without understanding the future. Innovating for an anticipated future is risky, and then getting it right is fortunate.

\section{Outline of a country:}

The view was that innovation can be inhibited by negativity at the country level, and the perceptions of a country's future and the morale of the people are important factors which determine the level of innovation. A negative mindset can stifle creativity and hope, and it can reduce the level of futures thinking. Participants also mentioned that historical events can affect innovation and entrepreneurial activity.

\subsubsection{Competitive Advantage}

\section{Owning the future:}

The view was that ownership of the future is not possible, but that major disruptors can influence and direct society. As an example, one participant said, "their technology or service or whatever becomes so ingrained into the way of life, that in some way, shape or form, they control you."

\section{Competitive environments:}

The view was that entrepreneurs can gain a competitive advantage, by incorporating the future when innovating. Gaining insight on the future, ahead of competitors, provides an advantage, and the further out one can see into the future, the more significant the advantage will be. Participants mentioned that people are attempting to understand the future all the time, and the competitive environment is growing rapidly.

Participants mentioned that understanding trends help entrepreneurs seize opportunities ahead of competitors, when they arrive in the future. One participant said, "So when other people are caught unaware, the entrepreneur takes advantages of that situation." The view was that entrepreneurs need to continuously look for opportunities, to disrupt ahead of competitors. One participant mentioned that the best innovations appear quietly, and disrupt before competitors can replicate them.

Participants mentioned that it is easy to identify the major players who shape the future, but the dynamics are changing. As an example, one participant said, "look at the mining companies. Look at Anglo American. Look at huge companies that existed. They are just crumbling so much faster. Look at the big banks. What do you think is going to happen?".

Another view was that third-world countries are not in the "innovation race", because resources are limited. Participants mentioned that companies with the right skills and resources will have a competitive advantage in the future.

\subsubsection{Acclaimed Entrepreneurs}

The predominant view was that acclaimed entrepreneurs (Elon Musk, etc.) are not necessarily distinct in their ability to understand the future, but are unique in their ability to identify problems and solve them. Participants also mentioned that acclaimed entrepreneurs are passionate about customers, and give them what they want. The view was that they can see many different futures, they are abstract thinkers, curious problem solvers, prepared and well-calculated, and great at selling.

Another view was that access to financial resources helps them experiment and take risks. It was also mentioned that they have access to the right networks, and they have powerful teams. As an example, one participant said, "don't discount the means at his disposal. Musk has the greatest advantages a human could have. Right place, right time, right family. Right connections. And specifically, right money".

\section{Discussion}

\subsection{How Do Entrepreneurs View the Future?}

The results show that entrepreneurs are mostly negative about the future. Political uncertainty and infrastructure issues play a central role in shaping people's perceptions of the future. Entrepreneurs feel that 
the business environment is challenging, and that there is lack of support from government. At the same time, one may argue that entrepreneurs are complacent about the future, and display little leadership initiative, and may have become over-reliant on government to create the right ecosystems.

This highlights certain futures dispositions. The assumption might be that government is responsible for the future, or that nobody is truly responsible for the future. The latter case implies that futures simply arrive. Also, government may not necessarily be in the best position to create the future, especially if it lacks leadership.

Entrepreneurs have visions of hope and positivity. South Africa is still overcoming historical injustices, and this takes time. As things improve, entrepreneurs are becoming increasingly optimistic that the future will bring opportunity. There were views that the future could swing in either direction. It seems that entrepreneurs struggle to predict the future, and that they are not in control of the future. It is easy to believe that entrepreneurs are indeed not creating the future, but are instead waiting for it to arrive.

Most entrepreneurs view the future as uncertain and surprising. Entrepreneurs mention that the environment is continually changing, and disruptions suddenly appear. Entrepreneurs also view the future as unknown and difficult to predict. Based on these views, it is apparent that most entrepreneurs struggle to foresee change in the external environment, and are unable to gain a grip on the future. A lack of foresight and inadequate use of futures methods leads to surprise futures (Vecchiato and Roveda, 2010).

In contrast, some entrepreneurs share contradictory viewpoints, and said that the future was not surprising and unexpected. These entrepreneurs attempt to understand the direction of specific futures, like technology and industry, but futures in general, are not considered, and this leads to a narrow scope. A handful of entrepreneurs felt that uncertainty could be minimised, but not avoided, this shows a basic understanding of futures, but it is still generally limited.

Entrepreneurs see traditional business structures changing from hierarchical to flat, to remain relevant in the future. Uncertain environments are forcing organisations to become smaller and more agile. The view is that the future will be made up of many smaller organisations and fewer large corporations, and that traditional economic drivers are changing. Considering these views, it shows that entrepreneurs see opportunity in the future, but nothing leads us to believe that they are doing anything about it: A common thread throughout is that entrepreneurs seem to wait for the future to unfold, instead of creating it (Hines and Bishop, 2006).

Entrepreneurs are generally concerned and worried about future change. Change is rapid, and innovations are changing the norms. Exponential change leads to uncertainty, which intensifies when entrepreneurs are not prepared. Entrepreneurs fail to scan their environments effectively, and the depth of analysis is narrow, this means the future is not prepared, but instead guessed.

Concerning views of the future seem usual. Entrepreneurs realise that future intervention is needed. However, the views mentioned imply that entrepreneurs may be reluctant to change themselves, and there is little to suggest that they are willing to be more proactive. Attempting to correct problems to realise better futures requires ongoing effort, which is not evident. Other concerning factors of the future involve ethical and moral issues, and again there seems to be a lack of intervention from entrepreneurs. It appears that entrepreneurs are concerned about certain futures, but yet nothing is done, and the future is left to unfold.

In summary, entrepreneurs seem disconnected from the future. Ideally, entrepreneurs should be controlling and creating the future, but instead they let the future unfold (Hines and Bishop, 2006). This may imply that entrepreneurship is dysfunctional. There is a lack of leadership and discussion around the future, and everyone seems to be ignoring it. It is unclear who is taking responsibility for the future. Taking a step back, this raises three pressing questions:

1. Who is responsible for the future?

2. Can entrepreneurs afford to be complacent about the future?

3. Can entrepreneurs ignore the future, without adequately studying it?

\subsection{How Do Entrepreneurs Engage and Make Sense of the Future?}

Entrepreneurs make an effort to engage the future, but it is mostly limited. Understanding the future is regarded as an intuitive exercise and a "fun thing to do"; this is positive because it points towards entrepreneurs getting creative. Entrepreneurs use the future as a guiding vision to inform immediate decisions and actions. They also consider the future distant, and not real, and many believe that once the future is set, they need to stick to it. This leads us to believe that entrepreneurs are not serious about the future, and their understanding of it is simple. Ideally, entrepreneurs should be engaging and shaping the future, but it seems they are not.

Some entrepreneurs feel they are ill-equipped to address the future, stating that time and resources are 
limited. Entrepreneurs may be hiding behind excuses, and they can perhaps do well by changing their perspective. Entrepreneurs need to appreciate the value in understanding the future. Entrepreneurs can easily sign up for training, organise themselves better, or seek support from others.

A similar approach to personal futures is followed, in that entrepreneurs do not set aside adequate time to consider their futures, even though they are well aware of its importance. Most entrepreneurs have a general idea of the future, and planning is mostly done intuitively. Again, this approach to the future shows that it is of limited importance. Entrepreneurs need to dedicate time to the future, stop ignoring the future, and connect to the future; otherwise, it will move on without them.

Entrepreneurs generally follow the obvious future trends, to keep up with the future. The obvious trends are easy to see, but the future is mainly shaped by trends that are not initially apparent. Entrepreneurs need to broaden their perspective to understand the future better (Rohrbeck and Schwarz, 2013).

Interesting to note, entrepreneurs, place little significance on government's ability to influence the future, and put more importance on technology and social factors. This finding raises the following five questions around who or what predominantly shapes and drives the future:

1. Are futures shaped by technology, which may generally be an exogenous factor?

2. Is society shaping futures by deciding which technologies are relevant? the future?

3. Are these two leading factors (technology and society) impacting government's ability to influence

4. If entrepreneurs are not taking charge, and governments are not able to have a voice, who takes responsibility for the future?

5. If futures shaping is left to technology and society, are futures left to arrive?

Entrepreneurs mostly depend on past events to construct images of the future, while others neglect to study the future at all, because it seems too distant. Building on the past and current is incremental, and RI cannot happen when entrepreneurs build on past ideas to shape the future. Entrepreneurs need to identify new markets and innovate, this then leads to radical innovations which shape the future. FS plays a vital role in this regard.

It is believed that multiple factors shape the future, and that its direction is not intentionally planned. Little shows that entrepreneurs believe they can shape the future. Entrepreneurs fit into systems and structures, and allow other factors to influence their decisions. Instead, they should make greater use of FS and AL (action learning) as a creative learning process, which could help entrepreneurs break the mould, by creating new futures (Inayatullah, 2006).

Entrepreneurs select information they believe to be credible, and then base their perceptions of the future on this. The results show that entrepreneurs do consider the opinions of others, but ultimately, they formulate their own views, and this is positive. However, entrepreneurs generally lack variety and depth in the views they consider, and this leads to simple interpretations and understandings of the future.

Entrepreneurs believe tangible images of the future cannot be created, because the future changes all the time. Entrepreneurs generally have a vague, non-detailed, perception of the future, mainly because they do not unpack or study the future in depth, and the information used tends to be basic. The futures they create are unsettled by factors they believe cannot be controlled. However, this may simply be a matter of comprehensiveness of futures studies. Entrepreneurs can benefit from greater agility and open-mindedness. Studying futures should be worthwhile and insightful.

A point consistently raised was that first-world information is not relevant for third-world contexts. The view is that entrepreneurs should reduce their reliance on developed countries, and should become more independent themselves. Entrepreneurs can use FS to build confidence, which should lead to greater independence (Inayatullah, 2008).

Entrepreneurs typically use traditional and basic methods to forecast futures. There were mentions of using science fiction movies to understand the future, and this is encouraging, and in line with FS (Bergman et al., 2010). Speculative fiction can be used to stir creativity; these are precisely the right ingredients for entrepreneurial creativity. Comprehensive interpretation of the future requires extensive use of futures tools and methodologies. The methods used by entrepreneurs are only enough to develop vague and shallow ideas of the future. FS have advanced from traditional forecasting methods to SF (Rohrbeck et al., 2007).

Entrepreneurs see financial risk in innovating for futures with extended timelines. They believe plans become irrelevant, because everything shifts. Entrepreneurs need to understand that the future does not need to be an exact destination. Building views of the future can provoke new ideas, that can be worked on now, and released before the future arrives. SF methods can help reduce risk and uncertainty, by preparing for the future (Heger and Rohrbeck, 2012).

In summary, entrepreneurs do not take the future seriously enough, and their understanding of it is 
vague. Entrepreneurs need to find solutions to help them connect to the future. They need to broaden their perspectives and study the future more comprehensively.

\subsection{How Do Entrepreneurs Incorporate the Future When Innovating?}

Entrepreneurs hold polar views regarding innovation and the future. On the one hand, they mention that innovation cannot exist without understanding the future, and on the other hand they believe that innovation is mainly concerned with solving today's issues. Entrepreneurs link innovation to the future in general, but they fail to link innovation to FS. FS activities help create images of the future, which stimulates innovation (Rohrbeck and Bade, 2012).

Entrepreneurs do not construct likely future scenarios, and then innovate according to or from this. Using FS to innovate - innovating from a futures perspective or a futures study - requires a commitment to RI. Entrepreneurs are generally more concerned about current issues. RI seems to be lacking in South Africa. Entrepreneurs are incremental innovators, and regard innovating for the future as risky, and this impacts their level of innovation.

New product failure is mainly seen as a failure to meet current consumer needs, rather than a failure to understand the future. Entrepreneurs do very well in scanning the environment to understand and solve immediate consumer needs, but seem to disregard future needs. Entrepreneurs believe that incremental innovation shapes futures, but there is little or no reason to believe this. Arguably, shaping the future significantly depends on RI. Rather, the question is, who is responsible for shaping the future, and what role do entrepreneurs have in this regard? Creativity and innovation can be derived from FS exercises. Merely building on past innovations is not going to significantly shape the future. Entrepreneurs would benefit from using SF tools to help scan for future customer needs (Rohrbeck and Schwarz, 2013).

Entrepreneurs turn to incremental innovations to avoid financial risk. They feel significant innovations are risky, because markets may not adopt them. A possible reason why entrepreneurs see the future as risky is because their understanding of the future is limited. Trying to innovate for an uncertain future is risky, but if entrepreneurs were more serious about and more experienced at studying the future, it would be less risky to innovate for the future in advance, and this could end up generating significant outcomes.

Entrepreneurs believe the sentiment of a country impacts innovation and entrepreneurial activity, either negatively or positively. Formulating compelling images of a desired future should induce excitement and positivity. Futures thinking enhances innovation and creative thinking (Inayatullah, 2008). Entrepreneurs need to depend more on themselves, and create the right ecosystems for their success. Entrepreneurs need to change the way they think; away from being influenced by external factors, and more towards believing in themselves.

It is believed that incorporating the future when innovating can lead to a competitive advantage. Entrepreneurs also accept that the further out one can see into the future, the greater the potential advantage. Entrepreneurs understand the benefits of incorporating the future, yet they seem passive in this regard. Entrepreneurs also believe that a lack of resources inhibits their ability to consider futures when innovating.

The way entrepreneurs interpret acclaimed entrepreneurs' (Elon Musk, etc.) abilities, is reflected by the way they approach innovation themselves. Entrepreneurs believe that acclaimed entrepreneurs are not distinct in their ability to consider futures, but are instead great at identifying problems and solving them. Again, they mention that an abundance of resources helps them become highly successful. One questions whether or not acclaimed entrepreneurs can afford to avoid the future, and innovating for the future?

In summary, entrepreneurs believe there is a general connection between innovation and the future, but they are unable to truly see the relationship between innovation and FS. Little goes to show that entrepreneurs are radical innovators; they believe innovating for the future is risky. FS can reduce risk and uncertainty and increase innovation capacity (Heger and Rohrbeck, 2012).

\section{Conclusion}

Leadership (vacuum): There is a general lack of responsibility regarding the future, and everybody seems to believe that somebody else will take charge. Futures shaping, and direction should be assigned, so that futures are not merely left to arrive. There seems to be general complacency regarding the future, and there needs to be greater collaboration and discussion around the future. Entrepreneurs need to understand the future and take charge of the future. Entrepreneurs also wait for the future to arrive before they respond to it, and this is in part why the future is seen to be risky and uncertain.

Entrepreneurs and the future: It may be acceptable or understandable for novice entrepreneurs to temporarily ignore the future during the initial stages of development; however, even this statement may be 
open to objection. The debate on the stages of entrepreneurial maturity cannot entirely ignore and disregard the future. The stages of entrepreneurial experience may perhaps be classified according to levels of futures understanding, such that experienced entrepreneurs are expected or required to be competent with regards to the future. It is alleged that a country's portfolio of entrepreneurs is incomplete and lacking without entrepreneurs who address the future. Entrepreneurs are detached from the future, and their understanding of it is vague and simplistic. There is room for entrepreneurs to develop and mature further, by learning how to incorporate FS methods more. The literature shows the importance of using FS, but it is not currently being fully exploited.

Entrepreneurs and innovation: RI is lacking, and incremental innovation is predominant. Entrepreneurs build on the past, and innovate around immediate consumer frustrations and issues. Entrepreneurship without RI means entrepreneurship is not fully functional or developed, and it will remain elementary. RI is seen as essential for successful and mature entrepreneurship. FS increases innovation capacity, by illuminating potential futures, and this is currently not exploited. Entrepreneurs need to be shown the link between FS and innovation. The literature shows that FS activities can help entrepreneurs foresee future change, which then increases innovation activities.

The key findings of the study are summarized in table 2 .

Table 2. A summary of the key findings

\begin{tabular}{|c|c|c|}
\hline Research Question & Themes & Key points \\
\hline $\begin{array}{l}\text { 1. Futures positions and } \\
\text { thinking: How do } \\
\text { entrepreneurs view the } \\
\text { future? }\end{array}$ & $\begin{array}{ll}- & \text { Outlook of the future } \\
- & \text { The future brings change } \\
- & \text { Preferred futures }\end{array}$ & $\begin{array}{l}\text { - Entrepreneurs are not creating the future enough, } \\
\text { but are instead waiting for it to unfold. } \\
\text { - The future is waited upon, and then responded to. } \\
\text { - The future is mostly uncertain, surprising and } \\
\text { unpredictable. }\end{array}$ \\
\hline $\begin{array}{l}\text { 2. Constructing futures: How } \\
\text { do entrepreneurs engage and } \\
\text { make sense of the future? }\end{array}$ & $\begin{array}{ll}- & \text { Considering futures } \\
- & \text { Factors influencing the } \\
& \text { future } \\
- & \text { Futures studies }\end{array}$ & $\begin{array}{l}\text { - Entrepreneurs do not take the future seriously, and } \\
\text { their understanding of it is vague and shallow. } \\
\text { - Futures study methods are basic and lack depth. } \\
\text { - There is a lack of leadership around the future; } \\
\text { nobody is taking responsibility for it. }\end{array}$ \\
\hline $\begin{array}{l}\text { 3. Innovation and the future: } \\
\text { How do entrepreneurs } \\
\text { incorporate the future when } \\
\text { innovating? }\end{array}$ & $\begin{array}{ll}- & \text { Innovation and the future } \\
- & \text { Competitive advantage } \\
- & \text { Acclaimed entrepreneurs }\end{array}$ & $\begin{array}{l}\text { - Entrepreneurs see a general connection between } \\
\text { innovation and the future, but they are unable to } \\
\text { recognize the relationship between innovation and } \\
\text { FS. } \\
\text { - FS is essential for innovation, but it is currently not } \\
\text { exploited by entrepreneurs in South Africa. }\end{array}$ \\
\hline
\end{tabular}

\subsection{Future Research}

The following areas are suggested for future research:

- An in-depth study to determine the extent to which FS contributes to entrepreneurs' creativity and innovation. The study can be carried out by hosting workshops where entrepreneurs are taught FS tools and methods. It can subsequently be measured and assessed whether entrepreneurs display a change in their level or knowledge of creativity and innovation.

- A comparative study between FS professionals, like strategists and futurists, and entrepreneurs, regarding the future. The expectation is that FS professionals are experienced in FS, but not in creative thinking and innovation, and the opposite is expected for entrepreneurs. The study should focus on bridging any potential gap.

- A study on acclaimed entrepreneurs (Elon Musk, etc.) and futures, to examine the extent to which acclaimed entrepreneurs consider the future, as well as the depth and sophistication of their use of FS methods, to determine the extent to which their successes and innovations are tied to an understanding of the future.

- The relationship between entrepreneurs' visions and futures.

- Case studies on the use of FS for innovation and entrepreneurship.

- Further research around futures leadership. Who is ultimately responsible for shaping and directing futures? It seems entrepreneurs are generally complacent about the future and wait for others, like government, to create it. However, if government lacks leadership, who takes charge of the future? And what role do entrepreneurs play in this regard? If nobody is responsible for the future, is the future left to 
itself? This can be further extended to metrics around futures leadership - the predominant drivers of the future in a particular country, and the extent by which various stakeholders impact and shape the future in a particular country.

- Research to investigate the role and place of government with regards to the future. Entrepreneurs seem to depend on government to create the perfect ecosystems. The study can further investigate whether or not government should indeed be responsible for the future.

- The impact and role of FS with regards to entrepreneurship health, entrepreneurship maturity, and entrepreneurship balance.

- The optimization of FS for entrepreneurship. The specific needs of entrepreneurs with regards to FS, alleviating the cost of FS to entrepreneurs, and increasing the benefits entrepreneurs derive from FS.

- FS support and intervention programs for entrepreneurs.

- Entrepreneurship training and development, and the introducing FS to entrepreneurship training and development.

\section{References}

Bergman, A., Karlsson, J. C. and Axelsson, J., 2010. Truth claims and explanatory claims - An ontological typology of futures studies. Futures, 42(8), pp.857-865.

Cook, C. N., Inayatullah, S., Burgman, M. A., Sutherland, W. J. and Wintle, B. A., 2014. Strategic foresight: how planning for the unpredictable can improve environmental decision-making. Trends in ecology and evolution, 29(9), pp.531-541.

Dator, J., 1996. Futures studies as applied knowledge. New thinking for a new millennium, pp.105-115.

Dator, J., 1998. The Future Lies Behind!. American Behavioral Scientist, 42(3), pp.298-319.

Detienne, D. R., Koberg, C. S. and Heppard, K. A., 2001. A fresh look at incremental and radical innovation in the entrepreneurial firm. USASBE/SBIDA 2001 National Conference in Orlando, Florida.

Farrington, T., Henson, K. and Crews, C., 2012. Research foresights: The use of strategic foresight methods for ideation and portfolio management. Research-Technology Management, 55(2), pp.26-33.

Fink, A. and Schlake, O., 2000. Scenario management-An approach for strategic foresight. Competitive Intelligence Review, 11(1), pp.37-45.

Godet, M., 2008. Strategic foresight la prospective. Cahiers du LIPSOR, Paris.

Heger, T. and Rohrbeck, R., 2012. Strategic foresight for collaborative exploration of new business fields. Technological Forecasting and Social Change, 79(5), pp.819-831.

Hicks, D., 2004. Teaching for tomorrow: how can futures studies contribute to peace education? Journal of Peace Education, 1(2), pp.165-178.

Hines, A., 2006. Strategic foresight: the state of the art. The futurist, 40(5), p.18.

Hines, A. and Bishop, P. J., 2006. Thinking about the future: Guidelines for strategic foresight. Washington, DC: Social Technologies.

Inayatullah, S., 1998. Causal layered analysis: Poststructuralism as method. Futures, 30(8), pp.815-829.

Inayatullah, S., 2006. Anticipatory action learning: Theory and practice. Futures, 38(6), pp.656-666.

Inayatullah, S., 2008. Six pillars: futures thinking for transforming. Foresight, 10(1), pp.4-21.

Kothari, C. R., 2004. Research methodology: Methods and techniques. NY: New Age International.

McKelvey, B. and Boisot, M., 2009. Redefining Strategic Foresight:'Fast'and 'Far'Sight via Complexity Science. Handbook of research on strategy and foresight, pp.15-47.

Mietzner, D. and Reger, G., 2005. Advantages and disadvantages of scenario approaches for strategic foresight. International Journal of Technology Intelligence and Planning, 1(2), pp.220-239.

Ramos, J. M., 2006. Dimensions in the confluence of futures studies and action research. Futures, 38(6), pp.642-655.

Ritchey, T., 2005. Futures studies using morphological analysis. Adapted from an article for the UN University Millennium Project: Futures Research Methodology Series, $14 . \quad$ [online] Available at: http://www.swemorph.com/pdf/futures.pdf [Accessed on 11 May 2018].

Robinson, J. B., 1990. Futures under glass: a recipe for people who hate to predict. Futures, 22(8), pp.820842.

Rohrbeck, R., Arnold, H. M. and Heuer, J., 2007. Strategic Foresight in multinational enterprises-a case study on the Deutsche Telekom Laboratories. ISPIM-Asia 2007 Conference, New Delhi, India - 9th-12th January 2007.

Rohrbeck, R. and Bade, M., 2012. Environmental scanning, futures research, strategic foresight and 
organizational future orientation: a review, integration, and future research directions. ISPIM Annual Conference 2012, Barcelona, Spain.

Rohrbeck, R. and Gemünden, H., 2008. Strategic foresight in multinational enterprises: building a best-practice framework from case studies. $R \& D$ Management Conference 2008 "Emerging methods in $R \& D$ management", Ottawa, Canada

Rohrbeck, R., Mahdjour, S., Knab, S. and Frese, T., 2009. Benchmarking report: strategic foresight in multinational companies. Berlin, Germany: European Corporate Foresight Group.

Rohrbeck, R. and Schwarz, J. O., 2013. The value contribution of strategic foresight: Insights from an empirical study of large European companies. Technological Forecasting and Social Change, 80(8), pp.15931606.

Slaughter, R. A., 1996. Futures studies: From individual to social capacity. Futures, 28(8), pp.751-762.

Slaughter, R. A., 1997. Developing and applying strategic foresight. ABN Report, 5(10), pp.13-27.

Slaughter, R. A., 2002. From forecasting and scenarios to social construction: changing methodological paradigms in futures studies. Foresight, 4(3), pp.26-31.

Vecchiato, R. and Roveda, C., 2010. Strategic foresight in corporate organizations: Handling the effect and response uncertainty of technology and social drivers of change. Technological Forecasting and Social Change, 77(9), pp.1527-1539. 